Article

\title{
Synthesis of Star-Shaped Boron Carbide Micro-Crystallites under High Pressure and High Temperatures
}

\author{
Vladimir P. Filonenko ${ }^{1}$, Pavel V. Zinin ${ }^{2, *}$, Igor P. Zibrov ${ }^{1}$, Alexander S. Anokhin ${ }^{3}$, \\ Elena V. Kukueva ${ }^{4}$, Sergey G. Lyapin ${ }^{1}\left[\right.$ and Vyacheslav Y. Fominski ${ }^{5}$ \\ 1 Institute for High Pressure Physics, Russian Academy of Sciences, 108840 Troitsk, Moscow, Russia; \\ filv@ns.hppi.troitsk.ru (V.P.F.); zibrov@hppi.troitsk.ru (I.P.Z.); slyapin@gmail.com (S.G.L.) \\ 2 Scientific-Technological Center of Unique Instrumentation, Russian Academy of Sciences, \\ 117342 Moscow, Russia \\ 3 Institute of Metallurgy and Materials Science, Russian Academy of Sciences, 119991 Moscow, Russia; \\ alexanderanokhin@yahoo.com \\ 4 National Research Center, Kurchatov Institute, 123182 Moscow, Russia; elena.kukueva@gmail.com \\ 5 Institute of Laser and Plasma Technologies, National Research Nuclear University MEPhI (Moscow \\ Engineering Physics Institute), 115409 Moscow, Russia; vyfominskij@mephi.ru \\ * Correspondence: zosimpvz@mail.ru; Tel.: +7-495-334-7674
}

Received: 1 November 2018; Accepted: 28 November 2018; Published: 30 November 2018

\begin{abstract}
We synthesized star-shaped pentagonal microcrystals of boron carbide with an extremely low carbon content $(\sim 5 \%)$, from m-carborane under high pressure (7 GPa) and high temperature (1370-1670 K). These crystals have five-fold symmetry and grow in the shape of stars. A 5-fold symmetry in large micron-sized crystals is extremely rare making this a striking observation.
\end{abstract}

Keywords: boron carbide; star-shaped; high pressure synthesis; quasicrystal

\section{Introduction}

Boron carbide is characterized by a unique combination of properties that makes it the material of choice for a wide range of engineering applications [1]. Boron carbide has attracted the attention of chemists, physicists, and material scientists because of its low density, high hardness, high melting point, excellent ballistic performance, high temperature semi-conductivity, and chemical inertness [2].

There are several theoretical predictions stating that boron-rich solids are great candidates for semiconducting quasicrystals because they have a variety of semiconducting crystalline structures with icosahedral clusters $\left(B_{12}\right)$ [3-5]. Several boron-rich quasi-crystalline structures have been obtained. Massive icosahedral quasicrystals were observed during the arc evaporation of carbon and boron [6]. Two dimensional (2D) boron carbide nanomaterials with a belt-like morphology, based on icosahedra were found in the material obtained by heating boron oxide in a graphite mold up to $1950{ }^{\circ} \mathrm{C}$ with an exposure for $1 \mathrm{~h}$ [7]. The size of such crystals reaches ten microns.

The effect of carbon concentration on the structure parameters of boron carbide obtained by self-propagating high-temperature synthesis was studied in more details in Ref. [8]. According to the phase diagram the parameters of the unit cell change only slightly, when the amount of carbon in the system is in the range from $5 \%$ to $8 \%$. In this report we demonstrate that the micron size quasicrystals of boron carbide with small carbon content $(\sim 5 \%)$ and a five-pointed star shape are formed under high pressure and high temperature (HPHT). The volume of the unit cell of these microcrystals appears to be the largest among all the boron carbide phases. The observation of pentagonal star-shaped boron carbide microcrystals has not been reported before. 


\section{Materials and Methods}

For high pressure synthesis we used 1,7-bis(hydroxymethyl)-m-carborane 99.7\% purity [9] with the formula $\mathrm{HOCH}_{2} \mathrm{CB}_{10} \mathrm{H}_{10} \mathrm{CCH}_{2} \mathrm{OH}$ (Aviabor, Dzerzhinsk, Russia) and its powder mixtures with lamp soot $99.0 \%$ purity (H. Schminke \& Co, Germany). The thermobaric treatment was carried out in a high pressure chamber type "toroid" in a pressure range from 5 to $8 \mathrm{GPa}$ and temperatures from 970 to $1770 \mathrm{~K}$. The exposure time varied from 30 to $120 \mathrm{~s}$. Lithographic stone cell was compressed between two hard metal anvils with a specific profile [10]. The scheme of the cell inserts was described in reference [11]. The temperature gradient over the sample height was about $100 \mathrm{~K}$.

HUBER Imaging Plate Guinier camera G670 (CuK $\alpha_{1}$ radiation, $\lambda=1.5405981 \AA$ A, Huber Technology, Tutzing, Germany) was used for X-ray diffraction measurements. Study of the microstructure and elemental composition analysis was conducted by a scanning electron microscope (SEM) FEI HELIOS NanoLab 660 equipped with AMETEK EDAX (Hillsboro, Oregon, USA, electron dispersive X-ray spectroscopy) microanalysis system. Raman spectra were collected at room temperature using TriVista 555 triple grating spectrometer with a liquid-nitrogen-cooled charge coupled device (CCD) detector. A $488 \mathrm{~nm}$ line of the $\mathrm{Ar}^{+}$ion laser was used for excitation. To avoid overheating or burning out of the samples, the laser power was kept at a minimum (approximately $0.5 \mathrm{~mW}$ ) and the Olympus BX51 (Olympus, Tokyo, Japan) microscope with $50 \times$ objective was used for laser focusing and scattered light collection. Positions of the Raman peaks were obtained by fitting peaks with Gaussian shape function using Grams 7.0 software (Paisley, UK) software Background correction was done using polynomial sextic spline functions imbedded in Grams 7.0 software.

\section{Results}

The m-carborane is a white powder. Under ambient pressure it has a melting point of $542 \mathrm{~K}$. The thermobaric treatments conducted at $7 \mathrm{GPa}$ demonstrate that under pressure $\mathrm{m}$-carborane remains stable at $1220-1270 \mathrm{~K}$. As the temperature increases above $1270 \mathrm{~K}$ it melts and decomposes. For 30-120 s, a novel phase of boron carbide emerges from the fluid phase.

The synthesized phase of boron carbide consists of individual crystals. The color of crystallites varies from light orange to burgundy indicating the presence of residual hydrogen in the crystal lattice [12]. The most interesting feature of the novel phase is that its crystals have the form of a pentagonal star (Figure 1). Such morphology of the particles reflects their cyclic twinning along axes of the fifth order. Symmetry of the fifth order is a characteristic feature of quasicrystals [13]. The particles' size depends on the synthesis parameters and the temperature gradient in the chamber and ranges from 0.5 to $5.0 \mu \mathrm{m}$. It is assumed that the crystals have good faceting because they are surrounded by $\mathrm{C}-\mathrm{H}$ fluid formed during the $\mathrm{m}$-carborane decomposition.
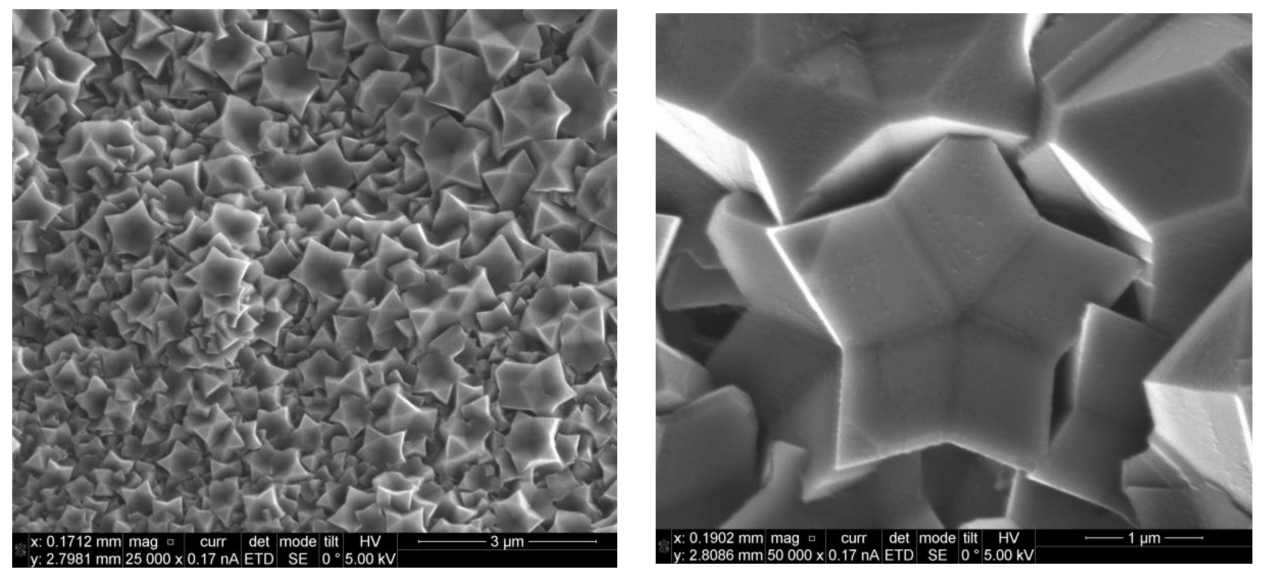

Figure 1. Scanning electron microscope (SEM) images of star-shaped pentagonal boron carbide microcrystals taken at different magnifications. 
The X-ray diffraction patterns with the Miller indices of the quenched samples are shown in Figure 2. The $\mathrm{X}$-ray spectrum of the $\mathrm{B}_{13} \mathrm{C}_{2}$ was added as a reference. The set of peaks of the star-shaped micro-crystallites is similar to that of $\mathrm{B}_{13} \mathrm{C}_{2}$, indicating a similarity of the symmetry of the unit cells. The X-ray pattern of the carbide obtained from $\mathrm{m}$-carborane was indexed with a hexagonal lattice. The volume of the unit cell was found to be 343.16(5) $\AA^{3}(a=5.6812(6), c=12.277(6) \AA)$ and appeared to be the largest among boron carbide phases. The numbers in parentheses are estimated standard deviations. Because of the large number of defects, the diffraction peaks of the star-shaped boron carbide are broad (Figure 2). It did not allow us to refine its structure using the Rietveld method.

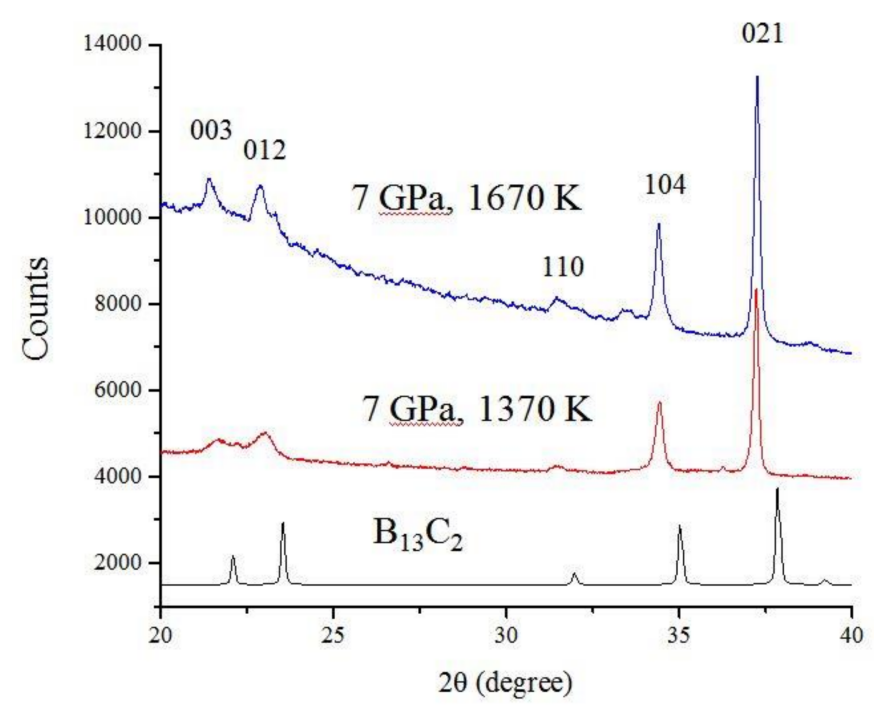

Figure 2. X-ray diffraction patterns of boron carbide phases: $\mathrm{B}_{13} \mathrm{C}_{2}$; star-shaped microcrystals of boron carbide obtained after heating to $1370 \mathrm{~K}$ at $7 \mathrm{GPa}$ and after thermobaric treatment at $7 \mathrm{GPa}$ and $1670 \mathrm{~K}$.

Raman spectra of star-shaped boron carbide microcrystals have also rather wide peaks (Figure 3) probably because of the small size of carbide crystals and numerous defects inside the microcrystals.

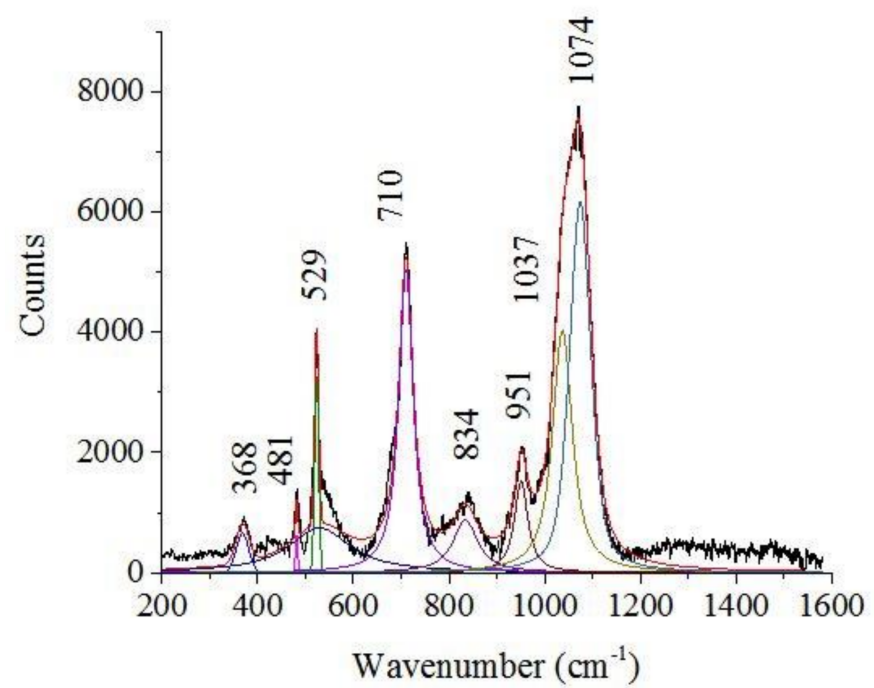

Figure 3. Raman spectrum of star-shaped boron carbide microcrystals synthesized from M-carborane at $7 \mathrm{GPa}$ and $1370 \mathrm{~K}$. The solid black line is the measured Raman spectrum, varicolored Gaussian shaped peaks are results of the Grams software fitting. 


\section{Discussion}

The presence of a large number of twins and packing defects in boron carbides with low carbon content was confirmed by transmission electron microscopy (TEM) [14,15]. The pattern of Raman peaks of the star shaped boron carbide microcrystals is similar to that of the single crystal boron carbide (20 at\% carbon) measured in Ref. [16]. However, there is a significant difference in the height ratio of Raman peaks at 481 and $529 \mathrm{~cm}^{-1}$. The sharp peak at $481 \mathrm{~cm}^{-1}$ is associated with stretching of three-atom chains and the $531 \mathrm{~cm}^{-1}$ mode represents the rigid rotation of icosahedra [16]. The difference in relative intensity of these peaks may be attributed to the effect of the carbon concentration on the Raman scattering cross-section of the correspondent vibrations. For instance, a strong dependence of Ti concentration on relative intensity of Raman peaks was found in Raman spectra of titanomagnetite [17].

Five-fold twinned boron carbide nanowires were revealed in a product of solid state reaction of $\mathrm{Fe}_{3} \mathrm{O}_{4}, \mathrm{BaO}$ and amorphous boron powders at $1100{ }^{\circ} \mathrm{C}$ for $2 \mathrm{~h}$ in a tube furnace protected by a flowing Ar atmosphere [18]. It was suggested that the source of carbon was the remains of the organic binder used to form the pellet. The five-fold cyclic twinning relationship was confirmed by systematic axial rotation of electron diffraction. Recently, the controlled synthesis of multilayered structure of star-shaped $\mathrm{B}_{6} \mathrm{O}$ particles was reported [19]. The literature review revealed that the formation of star-shaped microcrystalline particles was not observed in the boron carbide system.

The formation of star-shaped microcrystals was accounted for at a low concentration of carbon in the boron carbide system. Measurements of the elemental composition of individual boron carbide microcrystals showing a low carbon content $(\sim 5 \%)$ are in an agreement with the results presented in Refs. $[8,20]$, in which the influence of the boron content on the lattice parameter of boron carbide was analyzed. The unit cell volume only slightly changes in the carbon concentration range of $5 \%-10.5 \%$ [8]. In this concentration range the average value is around $340 \AA^{3}$. It was found that the cell volume decreases from $339.5 \mathrm{~A}^{3}$ to $328.0 \mathrm{~A}^{3}$ with an increase in carbon concentration from $8 \%$ to $20 \%$ atom. It indicates that the replacement of boron atoms by carbon in the chain connecting the icosahedra leads to a decrease in cell parameters. The parameter $a$ of the rhombohedral unit cell decreases from $5.643 \AA$ to $5.595 \AA$ when the composition of boron carbide phase changes from $B_{11} C$ to $B_{4.3} C[1,20]$. At the same time, the parameter $c$ of the rhombohedral unit cell remains unchanged in the composition range from $\mathrm{B}_{11} \mathrm{C}$ to $\mathrm{B}_{13} \mathrm{C}_{2}$ and then decreases from 12.173 to $12.07 \AA$.

Therefore, the concentration of carbon in our crystals may be even smaller than $5 \%$, taking into account the large unit cell volume (343.16(5) $\left.\AA^{3}, a=5.6812(6), c=12.277(6) \AA\right)$. The star-shaped microcrystals have a maximal size of the unit cell among all known boron carbide phases. The lattice parameters of boron carbide depend on the number and positions of carbon atoms in the icosahedra-binding chain. Hydrogen can be incorporated in the boron carbide rhombohedral framework without increasing the volume of the unit cell [21].

The pentagonal stars were synthesized only from $\mathrm{m}$-carborane. When an equal mass of the lamp soot (particle size from 20 to $90 \mathrm{~nm}$ ) and the m-carborane were mixed, the transformation path has changed: the mixture transforms to graphite or diamond phases depending on the HPHT. A disordered graphite-like phase and poorly crystallized boron carbide were formed at a pressure of $6 \mathrm{GPa}$ and a temperature of $1370 \mathrm{~K}$. Increasing the pressure and the temperature of the treatment, led to a phase transition of graphite to diamond. At $8 \mathrm{GPa}$ and $1870 \mathrm{~K}$, the mixture transformed into two phases: boron carbide and boron doped diamond. The volume of the boron carbide unit cell was found to be $325.7 \AA^{3}$ ( $a=5.59 \AA, c=12.05 \AA$ ) corresponding to the composition of $\mathrm{B}_{4} \mathrm{C}$. No star-shaped microcrystalllites were detected.

\section{Conclusions}

In summary, here we report the formation of star-shaped pentagonal microcrystals of boron carbide with extremely low carbon content $(\sim 5 \%)$ from m-carborane under high pressure of $7 \mathrm{GPa}$ and temperature of $1370 \mathrm{~K}$. The microcrystals exhibit a five-fold symmetry and grow in the shape 
of stars. The five-fold symmetry is a characteristic feature of quasi-crystalline solids. The unusual shape of the pentagonal microcrystals makes them unique for developing novel micro-machines and semiconductor micro-devices.

Author Contributions: V.P.F. conducted the HP-HT synthesis, P.V.Z. initiated this study, I.P.Z. performed the X-ray study, A.S.A. the equipment and calibration of high-pressure cells, E.V.K. performed the electron microscopy study, S.G.L. performed the Raman spectra study, V.Y.F. performed the interpretation of the Raman spectra.

Funding: This work was financially supported by Russian Science Foundation grant (RSF 17-12-01535).

Conflicts of Interest: The authors declare no conflicts of interest.

\section{References}

1. Domnich, V.; Reynaud, S.; Haber, R.A.; Chhowalla, M. Boron Carbide: Structure, Properties, and Stability under Stress. J. Am. Ceram. Soc. 2011, 94, 3605-3628. [CrossRef]

2. Andrievski, R.A. Micro- and nanosized boron carbide: Synthesis, structure and properties. Russ. Chem. Rev. 2012, 81, 549-559. [CrossRef]

3. Kimura, K.; Hori, A.; Yamashita, H.; Ino, H. Crystalline structures as an approximant of quasi-crystal and distortion of $\mathrm{B}_{12}$ icosahedron in boron-rich solids-search for semiconducting quasicrystal. Phase Transit. 1993, 44, 173-182. [CrossRef]

4. Weygand, D.; Vergergaugry, J.L. Model of a covalent pure boron quasi crystal. C. R. Acad. Sci. Ser. II 1995, $320,253-257$.

5. Werheit, H.; Schmechel, R.; Kimura, K.; Tamura, R.; Lundström, T. On the electronic properties of icosahedral quasicrystals. Solid State Commun. 1996, 97, 103-107. [CrossRef]

6. Wei, B.Q.; Vajtai, R.; Jung, Y.J.; Banhart, F.; Ramanath, G.; Ajayan, P.M. Massive icosahedral boron carbide crystals. J. Phys. Chem. B 2002, 106, 5807-5809. [CrossRef]

7. Xu, F.F.; Bando, Y. Formation of two-dimensional nanomaterials of boron carbides. J. Phys. Chem. B 2004, 108, 7651-7655. [CrossRef]

8. Ponomarev, V.I.; Kovalev, I.D.; Konovalikhin, S.V.; Vershinnikov, V.I. Ordering of carbon atoms in boron carbide structure. Crystallogr. Rep. 2013, 58, 422-426. [CrossRef]

9. Grimes, R.N. Carboranes; Elsevier: Amsterdam, The Netherlands, 2011.

10. Khvostantsev, L.G.; Slesarev, V.N.; Brazhkin, V.V. Toroid type high-pressure device: History and prospects. High Press. Res. 2004, 24, 371-383. [CrossRef]

11. Filonenko, V.P.; Zibrov, I.P. High-pressure phase transitions of $\mathrm{M}_{2} \mathrm{O}_{5}(\mathrm{M}=\mathrm{V}, \mathrm{Nb}, \mathrm{Ta})$ and thermal stability of new polymorphs. Inorg. Mater. 2001, 37, 953-959. [CrossRef]

12. Kondrin, M.V.; Nikolaev, N.A.; Boldyrev, K.N.; Shulga, Y.M.; Zibrov, I.P.; Brazhkin, V.V. Bulk graphanes synthesized from benzene and pyridine. CrystEngComm 2017, 19, 958-966. [CrossRef]

13. Nehl, C.L.; Liao, H.W.; Hafner, J.H. Optical properties of star-shaped gold nanoparticles. Nano Lett. 2006, 6, 683-688. [CrossRef] [PubMed]

14. Cheng, C.; Reddy, K.M.; Hirata, A.; Fujita, T.; Chen, M. Structure and mechanical properties of boron-rich boron carbides. J. Eur. Ceram. Soc. 2017, 37, 4514-4523. [CrossRef]

15. Xie, K.Y.; Domnich, V.; Farbaniec, L.; Chen, B.; Kuwelkar, K.; Ma, L.N.; McCauley, G.W.; Haber, R.A.; Ramesh, K.T.; Chen, M.W.; et al. Microstructural characterization of boron-rich boron carbide. Acta Mater. 2017, 136, 202-214. [CrossRef]

16. Tallant, D.R.; Aselage, T.L.; Campbell, A.N.; Emin, D. Boron carbide structure by Raman spectrocopy. Phys. Rev. B 1989, 40, 5649-5656. [CrossRef]

17. Zinin, P.; Tatsumi-Petrochilos, L.; Bonal, L.; Acosta, T.; Hammer, J.; Gilder, S.; Fuller, M. Raman spectroscopy of titanomagnetites: Calibration of the intensity of Raman peaks as a sensitive indicator for their Ti content. Am. Mineral. 2011, 96, 1537-1546. [CrossRef]

18. Fu, X.; Jiang, J.; Liu, C.; Yuan, J. Fivefold twinned boron carbide nanowires. Nanotechnology 2009, 20, 365707. [CrossRef] [PubMed]

19. Solodkyi, I.; Demirskyi, D.; Sakka, Y.; Vasylkiv, O. Synthesis of Multilayered Star-Shaped $\mathrm{B}_{6} \mathrm{O}$ Particles Using the Seed-Mediated Growth Method. J. Am. Ceram. Soc. 2015, 98, 3635-3638. [CrossRef] 
20. Werheit, H. Boron carbide: Consistency of components, lattice parameters, fine structure and chemical composition makes the complex structure reasonable. Solid State Sci. 2016, 60, 45-54. [CrossRef]

21. Shirasu, Y.; Yamanaka, S.; Miyake, M. Hydrogen solubility in boron carbide. J. Alloys Compd. 1992, 190, 87-90. [CrossRef]

(c) (P)

(C) 2018 by the authors. Licensee MDPI, Basel, Switzerland. This article is an open access article distributed under the terms and conditions of the Creative Commons Attribution (CC BY) license (http:/ / creativecommons.org/licenses/by/4.0/). 